\title{
Extraction of Cefquinome from Food by Magnetic Molecularly Imprinted Polymer
}

\author{
Aggarwal $\mathbf{S}^{1}$, Rajput $\mathbf{Y S}^{1^{\star}}$, Sharma $\mathbf{R}^{2}$ and Pandey AK ${ }^{1}$ \\ ${ }^{1}$ Animal Biochemistry Division, National Dairy Research Institute, India \\ 2 Dairy Chemistry Division, National Dairy Research Institute, India
}

*Corresponding author: Rajput YS, Emeritus Scientist, Animal Biochemistry Division, National Dairy Research Institute, Karnal-132001, India, Tel: +91-9466653595; Email: ys_rajput@rediffmail.com

Received date: October 26, 2016; Accepted date: December 02, 2016; Published date: December 05, 2016

Copyright: ( 2016 Aggarwal S, et al. This is an open-access article distributed under the terms of the Creative Commons Attribution License, which permits unrestricted use, distribution, and reproduction in any medium, provided the original author and source are credited.

\begin{abstract}
Objectives: Cefquinome is a fourth generation cephalosporin with broad spectrum antimicrobial activity. It is commonly used against respiratory tract diseases, acute mastitis, calf septicemia and foot rot in livestock. Clean-up step in sample preparation is invariably required for avoiding interferences in assay from other components. It is envisaged to prepare molecular imprinted based polymer with desired selectivity for cefquinome. Method: Imprinted polymer was synthesized over the surface of magnetite using methacrylate (monomer) acid and ethyleneglycoldimethacrylate (crosslinker) in the presence of cefquinome (imprint molecule). Magnetite was prepared by co-precipitation of $1.98 \mathrm{~g} \mathrm{FeCl} 2 \cdot 4 \mathrm{H}_{2} \mathrm{O}$ and $5.41 \mathrm{~g} \mathrm{FeCl} \cdot 6 \mathrm{H}_{2} \mathrm{O}$. Magnetic non-imprinted polymer was prepared similarly in absence of cefquinome. Selectivity in different solvent was calculated from partition coefficient values in imprinted and non-imprinted polymers. Result: Selectivity of imprinted polymer over non-imprinted polymer was dependent on nature of solvent and $\mathrm{pH}$. Binding of cefquinome was highly selective in acetonitrile. Imprinted polymer lacks selectivity in methanol and $1 \mathrm{M} \mathrm{NaCl}$. lonic interaction between quinolinium ion in cefquinome and carboxylate anion in polymer appears to be major force for recognition of cefquinome by imprinted polymer. Prepared polymer extracted cefquinome from milk, honey, egg and water and extraction efficiency was in the range of $74-93.7 \%$. Conclusion: Selectivity of magnetic imprinted polymer must be determined in different solvents and this will enable selecting binding and elution conditions during extraction of imprint molecule.
\end{abstract}

Keywords: Cefquinome; Imprinted polymer; Magnetite; Selectivity; Extraction; FTIR; Polymerization

\section{Introduction}

Cefquinome is a fourth generation cephalosporin with broad spectrum antimicrobial activity and is resistant to $\beta$-lactamase $[1,2]$. Chemically cefquinome is $(6 \mathrm{R}, 7 \mathrm{R})-7-[[(2 \mathrm{Z})-2-(2-$ Amino- $1,3-$ thiazol-4-yl)-2-methoxyiminoacetyl]amino]-8-oxo-3-(5,6,7,8-

tetrahydroquinolin-1-ium-1-ylmethyl)-5-thia-1-

azabicyclo[4.2.0] oct-2-ene-2-carboxylate (Figure 1). It is commonly used against respiratory tract diseases, acute mastitis, calf septicemia and foot rot in cattle and also respiratory diseases, Metritis-MastitisAgalactia Syndrome in sows. Indiscriminate use of cefquinome in dairy industry leads to retarded milk fermentation, toxicological effects and hypersensitivity, thereby affecting public health. European Union has established a maximum residual limit of cefquinome in milk (20 $\mu \mathrm{g} / \mathrm{Kg})$, fat $(50 \mu \mathrm{g} / \mathrm{Kg})$, liver $(100 \mu \mathrm{g} / \mathrm{Kg})$, kidney $(200 \mu \mathrm{g} / \mathrm{Kg})[3,4]$.

Preparation of sample is usually required before food analysis [5]. Available sample preparation techniques are based on liquid-liquid extraction [6], membrane extraction [7,8], solid-phase extraction $[9,10]$, microwave assisted extraction $[11,12]$ and ultrasonic assisted extraction [13,14]. These methods lack specificity and extracted material may contain large amount of undesired chemical entities which are often removed by another clean up step. Clean up protocols with enhanced specificity is integral part of molecular imprinted polymer (IP) which is synthesized from functional monomer and cross-linking monomer in the presence of target molecule.
Prior interaction of target molecule with monomer enables synthesis of polymer with pre-defined specificity. The target molecules are knocked-off from prepared polymer to create binding sites for target molecule in sample. IP has a molecular recognition site which is chemically and spatially complementary to the target molecules [15]. These polymers are stable at extreme $\mathrm{pH}$ and temperature, easy to prepare, involve low cost and are reusable. Such polymers have been prepared against widely different molecules including antibiotics [16-18], pesticides [19,20], heavy metals [21,22], drugs [23], lactate [24] and for different purposes such as artificial antibodies [25], catalyst [26], chemical sensors [27] and solid phase extraction [18]. Use of these materials in solid phase extraction requires negative or positive pressure generating pump or centrifuge machine, limiting its use with ease.

Magnetic imprinted polymers offer distinct advantage over nonmagnetic polymers in their ease of separation under magnetic field after binding to their target molecules. These particles are prepared by encapsulating inorganic magnetic particles in molecular imprinted polymers and thus retain magnetic properties and specificity for target analyte.

This has encouraged many workers to prepare magnetic imprinted polymers having specificity towards chloramphenicol [28], sulfonylurea [29], oxytetracycline [30], $\beta$-lactam antibiotic [31], protocatechuic acid [32], macrolide antibiotics [33], metronidazole [34], levofloxacin [35], polychlorinated biphenyls [36], erythromycin [37]. The present work focuses on synthesis of cefquinome specific magnetic polymer and its use in extraction of the antibiotic from food matrix. 


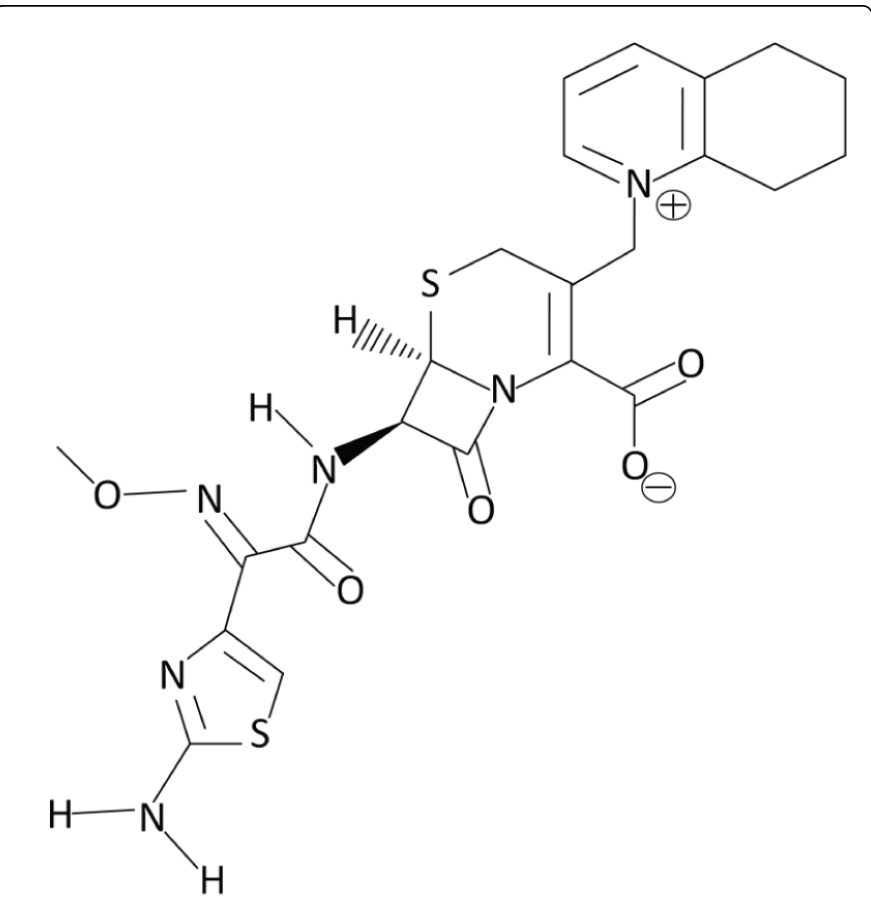

Figure 1: Structure of Cefquinome.

\section{Materials and methods}

\section{Materials}

Cefquinome sulphate, tetracycline, cefalexin, gentamicin, penicillin, ampicillin, methacrylic acid (MAA), ethyleneglycol dimethacrylate (EGDMA), oleic acid, iron (II) chloride $\left(\mathrm{FeCl}_{2} \cdot 4 \mathrm{H}_{2} \mathrm{O}\right)$, iron (III) chloride $\quad\left(\mathrm{FeCl}_{3} \cdot 6 \mathrm{H}_{2} \mathrm{O}\right)$, polyvinylpyrrolidone (PVP), azobisisobutyronitrile (AIBN) were purchased from Sigma Aldrich, USA. Methanol (HPLC grade), ethanol, acetic acid glacial and acetonitrile (HPLC grade) were procured from Hi-media, India.

\section{Food samples}

Milk samples were obtained from Institute cattle yard (NDRI). Honey was obtained from Dabar India, Ltd. Eggs were obtained from local market. These food samples were spiked with cefquinome stock solution $(100 \mu \mathrm{g} / \mathrm{mL})$ prepared in water.

\section{Preparation of magnetic imprinted polymer (MagIP)}

Preparation of $\mathrm{Fe}_{3} \mathrm{O}_{4}$ magnetite-oleic acid-EGDMA mix: Magnetite was prepared by co-precipitation method [38]. In brief, $1.98 \mathrm{~g}$ $\mathrm{FeCl}_{2} .4 \mathrm{H}_{2} \mathrm{O}$ and $5.41 \mathrm{~g} \mathrm{FeCl}_{3} \cdot 6 \mathrm{H}_{2} \mathrm{O}$ were dissolved in $100 \mathrm{~mL}$ deaerated water. The mixture was purged with nitrogen gas and stirred vigorously at temperature $80^{\circ} \mathrm{C}$. Then, $40 \mathrm{~mL} \mathrm{NaOH}$ solution $(2 \mathrm{~N})$ was added drop wise. After $1 \mathrm{~h}$, magnetic precipitates were separated with help of external magnet and washed several times with deaerated water. After washing, precipitates of magnetite were dried at $60^{\circ} \mathrm{C}$. One gram $\mathrm{Fe}_{3} \mathrm{O}_{4}$ magnetite (freshly prepared) and $1.0 \mathrm{~mL}$ oleic acid $(99 \%$ pure) were mixed together for 10 minutes. Then $3.77 \mathrm{~mL}$ EGDMA (98\% pure) was added and contents were mixed.
Preparation of preassembly solution: $1.0 \mathrm{mmol}$ cefquinome and 344 $\mu \mathrm{L}$ MAA (98.5\% pure) were added to $10 \mathrm{~mL}$ deaerated water to allow the interaction between MAA and cefquinome. The mixture was stirred for $10 \mathrm{~min}$.

Preparation of pre-polymerization mix: Magnetite-oleic acidEGDMA mix was mixed with preassembly solution and then the contents were sonicated for $30 \mathrm{~min}$.

Polymerization reaction: 0.4 g PVP was added to $100 \mathrm{~mL} 80 \%$ aqueous ethanol solution and the contents were heated to $60^{\circ} \mathrm{C}$ while purging nitrogen gas. Then, pre-polymerization mix and $3 \mathrm{~mL}$ AIBN ( $98 \%$ pure) were added. The contents were maintained at $60^{\circ} \mathrm{C}$ for $24 \mathrm{~h}$ under continuous stirring at $300 \mathrm{rpm}$. The prepared polymer was separated with the help of external magnet and washed several times with methanol: acetic acid $(8: 2 \mathrm{v} / \mathrm{v})$ mixture, till washings were free from cefquinome. The polymer was further washed three times with deaerated water and dried at $60^{\circ} \mathrm{C}$. Magnetic non-imprinted polymer was prepared similarly as MagIP, except cefquinome was omitted from pre-assembly solution.

\section{Characterization}

MagIP was characterized by scanning electron microscope (SEM; Carl Zeiss, Germany) and Fourier-transform infrared spectrometry (FT-IR Shimadzu, IR affinity, Japan).

\section{Selectivity of imprinted polymer}

Selectivity of prepared polymer was calculated by ratio of partition coefficient of cefquinome for imprinted and non-imprinted polymer in water, acetonitrile, methanol, $1 \mathrm{M} \mathrm{NaCl}$ and at $\mathrm{pH}$ range from 4 to 7 in aqueous buffer [39]. Polymers $(20 \mathrm{mg})$ were incubated with $2 \mathrm{~mL}$ cefquinome $(40 \mu \mathrm{g})$ prepared in different solvent for $24 \mathrm{~h}$ at $30^{\circ} \mathrm{C}$. Unbound cefquinome and other studied antibiotics were assayed in supernatant by measuring absorbance at $221 \mathrm{~nm}$. Bound antibiotic was calculated by subtracting unbound antibiotic from total antibiotic added.

\section{Cross-reactivity of cefquinome imprinted polymer}

$40 \mu \mathrm{g}$ each of antibiotics was incubated with $20 \mathrm{mg}$ polymer in 2 $\mathrm{mL}, 20 \mathrm{mM}$ phosphate buffer $(\mathrm{pH} 7.0)$ for $24 \mathrm{~h}$ at $25^{\circ} \mathrm{C}$. Bound antibiotic was calculated by subtracting unbound antibiotic from total antibiotic.

\section{Extraction of cefquinome from water, milk, honey and egg- white}

$40 \mathrm{mg}$ imprinted or non-imprinted polymer was conditioned in sequence with $3 \mathrm{~mL}$ methanol and $3 \mathrm{~mL}$ water. $2 \mathrm{~mL}$ water (degassed) or $2 \mathrm{~mL}$ of milk or $2 \mathrm{~g}$ honey or $2 \mathrm{~mL}$ egg-white was diluted to $16 \mathrm{~mL}$ with $\mathrm{H}_{2} \mathrm{O}$. Then, these diluted food samples were spiked with $200 \mu \mathrm{g}$ cefquinome (solubilised in $2 \mathrm{~mL}$ acetonitrile) and mixed with conditioned imprinted or non-imprinted polymer for $10 \mathrm{~min}$. Unbound cefquinome was collected with ten successive washings with $3 \mathrm{~mL}$ acetonitrile. The bound cefquinome was then eluted by successive elution with $3 \mathrm{~mL} 0.2 \mathrm{M} \mathrm{NaCl}$.

\section{Results and discussion}

Cefquinome imprinted polymer coated over magnetite was well furnished with magnetic property which leads to the easy separation of 
polymer from sample matrix after binding to target molecules. Magnetite and polymer act as a core and coat of magnetic imprinted polymer respectively. $4.2 \mathrm{~g}$ polymer was obtained from $4 \mathrm{mmol}$ MAA and 20 mmol EGDMA. Cefquinome imprinted polymer was spherical in shape, porous and was $630 \pm 143 \mathrm{~nm}$ in size (Figure 2). Polymer exhibited peak at $540 \mathrm{~cm}^{-1}$ (characteristic of $\mathrm{Fe}-\mathrm{O}$ bond stretching), $1150 \mathrm{~cm}^{-1}$ (C-O stretch), $1370 \mathrm{~cm}^{-1}$ (C-H rock), $1450 \mathrm{~cm}^{-1}(\mathrm{C}-\mathrm{H}$ bend), $1724 \mathrm{~cm}^{-1}\left(\mathrm{C}=\mathrm{O}\right.$ stretch) and $2350 \mathrm{~cm}^{-1}(\mathrm{C} \equiv \mathrm{N})$ in FTIR (Figure 3). $\mathrm{C}=\mathrm{O}$ stretch and $\mathrm{C}-\mathrm{O}$ stretch peaks imply that carboxyl groups are present on the surface of polymerized matrix and will be available for interaction with cefquinome. The peak at 2350 appears of nitrile group $(-\mathrm{C} \equiv \mathrm{N})$. AIBN is a nitrile containing compound and has been used as initiator in polymer formation. This compound is thermally decomposed and generates free radical which subsequently acts on monomer and cross-linker. In this process, nitrile group get attached to monomer and cross-linker and hence to the finished polymer.

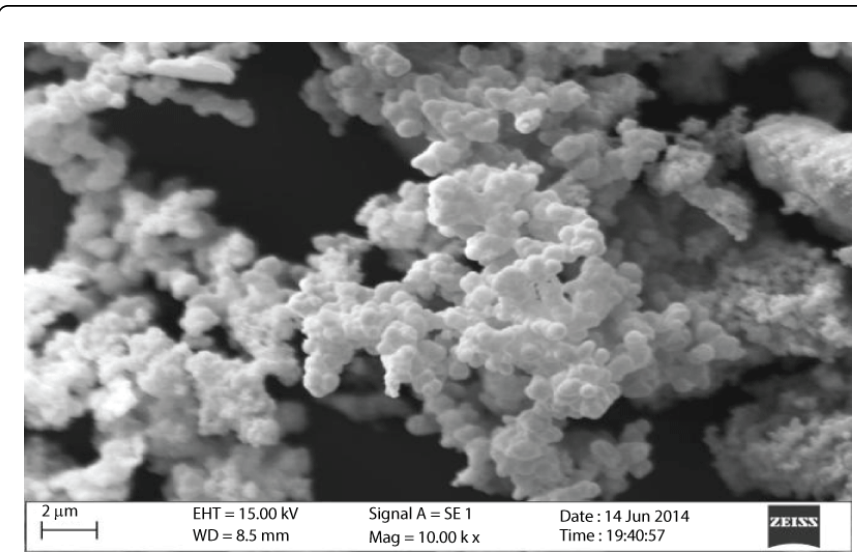

Figure 2: SEM image of cefquinome imprinted polymer.

Effect of solvent on binding of cefquinome: Binding capacity of imprinted and non-imprinted polymers was evaluated in $\mathrm{H}_{2} \mathrm{O}$, methanol, acetonitrile and $1 \mathrm{M} \mathrm{NaCl}$ (Table 1). The binding of cefquinome to imprinted polymer in acetonitrile was $62 \%$ which was distinctly higher than in water $(17 \%)$, methanol $(15 \%)$ and $1 \mathrm{M} \mathrm{NaCl}$ (5\%). In general, binding of cefquinome to non-imprinted polymer was low and was in the range of 5-15\% (Table 1).

Selectivity of imprinted polymer over non-imprinted polymer was strikingly high in acetonitrile (selectivity 31.01 ) in contrast to low selectivity in water (selectivity 1.84). Cefquinome failed to exhibit selectivity in methanol and $1 \mathrm{M} \mathrm{NaCl}$. Non-polar solvents such as acetonitrile and methanol facilitate non-covalent interactions.

Dipole moment of acetonitrile is 3.54 and thus it can easily facilitate conversion of carboxylic group present in polymer into dissociated state. $\beta$-Lactum nucleus in cefquinome is surrounded by quaternary quinolinium, an amino thiazolyl moiety and O-alkylated oxime. It exists as zwitter ion. Quaternary quinolinium cation of cefquinome can interact with carboxylate anion of polymerized matrix through ionic interaction.

Further, hydrogen bonds between carboxylic group of polymerized matrix and amino and carbonyl group of cefquinome can be easily formed and these may assist in orienting cefquinome to allow ionic interaction between quinolinium and carboxylate. Methanol is protic non-polar solvent and can form hydrogen bonds both with cefquinome and polymer.

Thus, in contrast to acetonitrile, methanol will disrupt hydrogen bond formation between cefquinome and carboxylate. Dipole moment of acetonitrile (3.54) is distinctly higher than either methanol (1.7) or water (1.85) and therefore, in comparison to methanol, acetonitrile has better capability to polarize carboxyl group available in polymerized matrix. This explains the selectivity of imprinted polymer towards cefquinome in acetonitrile, not in methanol.

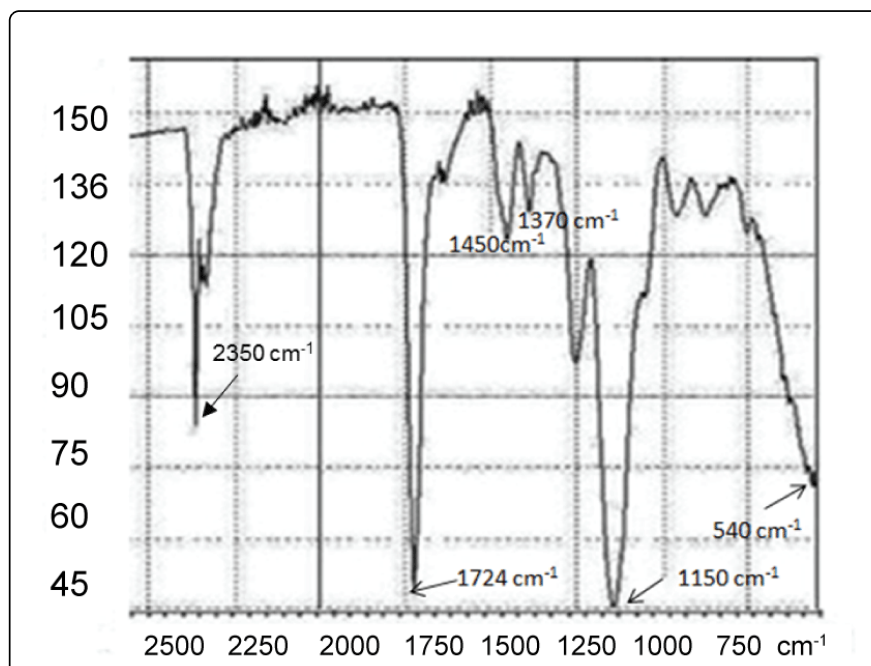

Figure 3: FT-IR of cefquinome imprinted polymer.

Effect of $\mathrm{pH}$ on binding of cefquinome: The second factor that influences the binding efficiency of cefquinome to imprinted polymer was $\mathrm{pH}$. At $\mathrm{pH} 7.0$ and at $\mathrm{pH} 6.0$, the binding of cefquinome was 53 and $46 \%$ respectively. Comparatively, at lower $\mathrm{pH}$ ( $\mathrm{pH} 5.0$ and 4.0 ), the binding was 3 to 7.5 -fold lower (Table 1). $\mathrm{pH}$ influences dissociation of carboxylic group. pKa of polymerized methacrylic acid is 5.5 [40] and thus at increased $\mathrm{pH}$, more number of carboxylic group will exist as carboxylate anion which can interact with quinolinium cation. At lower $\mathrm{pH}$, the number of carboxylate anion in polymer will be limited and will result in low binding. The ionic interaction between cefquinome and carboxylate anion is further supported by very low cefquinome binding (5\%) in presence of $1 \mathrm{M} \mathrm{NaCl}$ (Table 1).

Cross reactivity of cefquinome imprinted polymer: The specificity of cefquinome imprinted polymer was checked by studying the binding of three $\beta$-lactam group antibiotics (ampicillin, cefalexin, penicillin), gentamycin and tetracycline. The binding pattern of these antibiotics to imprinted and non-imprinted polymers suggests that binding of cefquinome to imprinted polymer is highly specific (Figure 4). Further, the binding of cefalexin and gentamycin to imprinted polymer was less than $7 \%$. However binding of penicillin was $20 \%$, and that of ampicillin and tetracycline about $30 \%$. The high selectivity of imprinted polymer towards cefquinome will be advantageous in separation methods. 
Citation: Aggarwal S, Rajput YS, Sharma R, Pandey AK (2016) Extraction of Cefquinome from Food by Magnetic Molecularly Imprinted Polymer.

Page 4 of 6

\begin{tabular}{|c|c|c|c|c|c|}
\hline Solvent & Polymer & Percentage bound & $\begin{array}{l}\text { Binding Capacity }(\mu \mathrm{g} / \mathrm{mg} \\
\text { beads) }\end{array}$ & Partition Coefficient & Selectivity \\
\hline \multirow{2}{*}{ Water } & Imprinted & 17 & 1.7 & 20.48 & \multirow{2}{*}{1.84} \\
\hline & Non-imprinted & 10 & 1.0 & 11.11 & \\
\hline \multirow{2}{*}{ Methanol } & Imprinted & 15 & 1.5 & 17.64 & \multirow{2}{*}{1.0} \\
\hline & Non-imprinted & 15 & 1.5 & 17.64 & \\
\hline \multirow{2}{*}{ Acetonitrile } & Imprinted & 62 & 6.2 & 136.15 & \multirow{2}{*}{31.01} \\
\hline & Non-imprinted & 5 & 0.5 & 5.26 & \\
\hline \multirow{2}{*}{$1 \mathrm{M} \mathrm{NaCl}$} & Imprinted & 5 & 0.5 & 5.26 & \multirow{2}{*}{1.0} \\
\hline & Non-imprinted & 5 & 0.5 & 5.26 & \\
\hline \multirow{2}{*}{$20 \mathrm{mM}$ Acetate buffer $\mathrm{pH} 4.0$} & Imprinted & 7 & 0.7 & 7.52 & \multirow{2}{*}{1.42} \\
\hline & Non-imprinted & 5 & 0.5 & 5.26 & \\
\hline \multirow{2}{*}{$20 \mathrm{mM}$ Acetate buffer pH 5.0} & Imprinted & 15 & 1.5 & 17.62 & \multirow{2}{*}{1.58} \\
\hline & Non-imprinted & 10 & 1 & 11.11 & \\
\hline \multirow{2}{*}{$20 \mathrm{mM}$ Phosphate buffer $\mathrm{pH} 6$} & Imprinted & 46 & 4.6 & 85.15 & \multirow{2}{*}{7.66} \\
\hline & Non-imprinted & 10 & 1 & 11.11 & \\
\hline \multirow{2}{*}{$20 \mathrm{mM}$ Phosphate buffer $\mathrm{pH} 7$} & Imprinted & 53 & 5.3 & 112.76 & \multirow{2}{*}{21.43} \\
\hline & Non-imprinted & 5 & 0.5 & 5.26 & \\
\hline
\end{tabular}

Table 1: Effect of solvent on binding, partition coefficient and selectivity of cefquinome magnetically imprinted polymer.

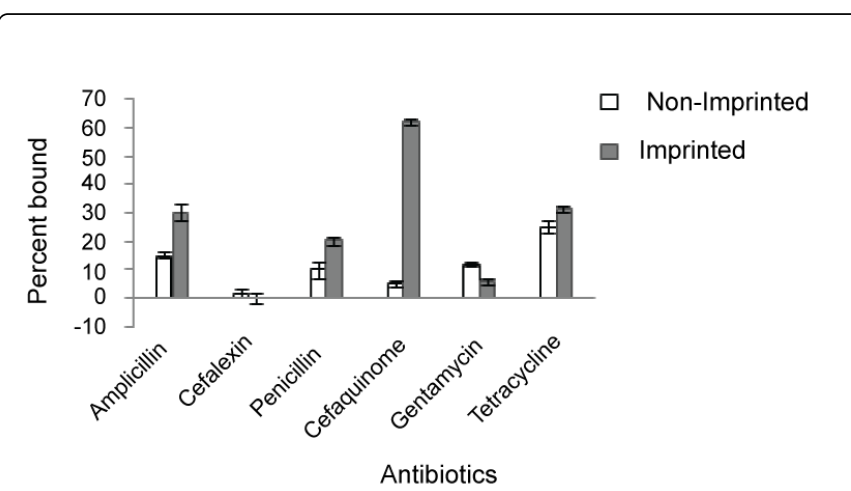

Figure 4: Binding of antibiotics to cefquinome magnetically imprinted polymers and non-imprinted polymer.

Extraction of cefquinome from food: The extraction capability of cefquinome imprinted polymer was evaluated for extraction of cefquinome from water, milk, honey and egg-white. For this purpose water, milk, honey and egg-white spiked with cefquinome were 10folds diluted with water to allow electrostatic interaction between cefquinome and imprinted polymer. The unbound cefquinome was washed with acetonitrile (Eluent 2-10) and bound cefquinome was eluted with $0.2 \mathrm{M} \mathrm{NaCl}$ (Eluent 11 onwards). The binding and elution profile indicates that cefquinome did bind to imprinted polymer in water or diluted food matrices and the bound cefquinome could be eluted with $0.2 \mathrm{M} \mathrm{NaCl}$ (Figure 5). Also, there was very little binding of cefquinome to non-imprinted polymer. The recovery from water, milk, honey and egg white was $80,93.7,92.8$ and $74 \%$, respectively.

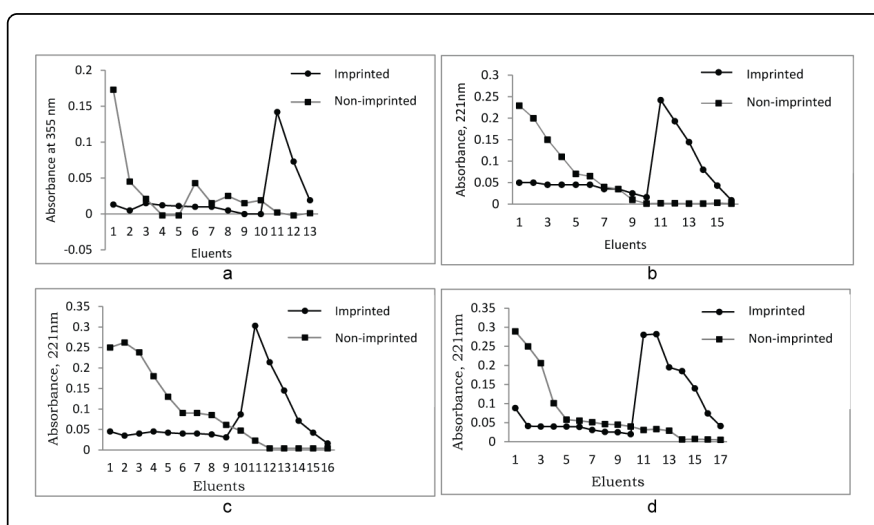

Figure 5: Extraction of cefquinome from a) water b) milk c) honey d) egg-white to imprinted and non imprinted polymer.

\section{Conclusion}

It is essential that binding of analyte is evaluated under different solvent conditions before concluding presence or absence of specific binding sites in imprinted polymer. This also helps in selecting appropriate conditions for analyte binding to imprinted polymer and its elution conditions. MagIP particles exist in colloidal state in absence of magnetic field and thus it is advantageous for quick interaction 
between analyte and dispersed particle. Also, MagIP can be easily separated by application of external magnetic field. Cefquinome imprinted magnetic polymer can be used for extraction of cefquinome from water and food matrices.

\section{Acknowledgment}

The authors are thankful to the National Funds for Basic, Strategic sand Frontier Application Research in Agriculture (NFBSFARA) for providing funds for research. Research fellowship to Sneha Aggarwal received during the research work from ICAR-NDRI, is also acknowledged.

Grants or other financial supporters of the study: Research grant from National Funds for Basic, Strategic sand Frontier Application Research in Agriculture (NFBSFARA). Research fellowship from ICAR-NDRI to Sneha Aggarwal during post-graduate studies.

\section{References}

1. Guerin-Faublee V, Carret G, Houffschmitt P (2003) In vitro activity of 10 antimicrobial agents against bacteria isolated from cows with clinical mastitis. Veterinary Record 152: 466-471.

2. Thomas E, Thomas V, Wilhelm C (2006) Antibacterial activity of cefquinome against equine bacterial pathogens. Vet Microbiol 115: 140-147.

3. (1990) Council Regulation 2377/90/EEC. Official Journal of the European Communities.

4. CVMP (2003) Cefquinome (Extension to Horses) Summary Report (3). EMEA/MRL/883/03-FINAL. European Agency for the Evaluation of Medicinal Products, London, UK.

5. Ridgway K, Lalljie SPD, Smith RM (2007) Sample preparation techniques for the determination of trace residues and contaminants in foods. J Chromatogr A 1153: 36-53.

6. Hamscher G, Priess B, Nau H, Panariti E (2005) Determination of colchicine residues in sheep serum and milk using high-performance liquid chromatography combined with electrospray ionisation ion trap tandem mass spectrometry. Anal Chem 77: 2421-2425.

7. Buldini PL, Ricci L, Sharma JL (2002) Recent applications of sample preparation techniques in food analysis. J Chromatogr A 975: 47-70.

8. Heems D, Luck G, Fraudeau C, Verette E (1998) Fully automated per column derivatization, online dialysis and high performance liquid chromatographic analysis of amino acids in food beverages and feedstuff. J chromatogr A 798: 9-17.

9. Paleologos EK, Kontominas MG (2004) On-line solid-phase extraction with surfactant accelerated on-column derivatization and micellar liquid chromatographic separation as a tool for the determination of biogenic amines in various food substrates. Anal Chem 76: 1289-1294.

10. Kuhnle GG, Dellaquila C, Low YL, Kussmaul M, Bingham SA (2007) Extraction and quantification of phytoestrogens in foods using automated solid-phase extraction and LC/MS/MS. Anal Chem 79: 9234-9239.

11. Cheng J, Liu M, Zhang X, Ding L, Yu Y, et al. (2007) Determination of triazine herbicides in sheep liver by microwave-assisted extraction and high performance liquid chromatography. Anal Chim Acta 590: 34-39.

12. You J, Zhang H, Zhang H, Yu A, Xiao T, et al. (2007) Determination of triazines in infant nutrient cereal-based foods by pressurized microwaveassisted extraction coupled with high-performance liquid chromatography-mass spectrometry. J Chromatogr B 856: 278-84.

13. Ruiz-Jimenez J, Priego-Capote F, de Castro MD (2004) Identification and quantification of trans fatty acids in bakery products by gas chromatography-mass spectrometry after dynamic ultrasound-assisted extraction. J Chromatogr A 1045: 203-210.
14. Rezic I, Horvat AJ, Babic S, Kastelan-Macan M (2005) Determination of pesticides in honey by ultrasonic solvent extraction and thin-layer chromatography. Ultrason Sonochem 12: 477-81.

15. Mosbach K, Ramstrom O (1995) The emerging technique of molecular imprinting and its future impact on biotechnology. Nat Biotechnol 14: 163-169.

16. Divya MP, Rajput YS, Sharma R (2010) Synthesis and application of tetracycline imprinted polymer. Anal Lett 43: 919-928.

17. Lata K, Sharma R, Naik L, Rajput YS, Mann B (2015) Synthesis and application of cephalexin imprinted polymer for solid phase extraction in milk. Food Chem 184: 176-182.

18. Urraca JL, Castellari M, Barrios CA, Moreno-Bondi MC (2014) Multiresidue analysis of fluoroquinolone antimicrobials in chicken meat by molecularly imprinted solid-phase extraction and high performance liquid chromatography. J Chromatogr A 1343: 1-9.

19. Zuo HG, Zhu JX, Zhan CR, Shi L, Xing M, et al. (2015) Preparation of malathion MIP-SPE and its application in environmental analysis. Environ Monit 187: 394.

20. He J, Song L, Chen S, Li Y, Wei H, et al. (2015) Novel restricted access materials combined to molecularly imprinted polymers for selective solid-phase extraction of organophosphorous pesticides from honey. Food Chem 187: 331-337.

21. Firouzzare M, Wang Q (2012) Synthesis and characterisation of a high selective mercury (II)-imprinted polymer using novel aminothiol monomer. Talanta 101: 261-266.

22. Fazelirad H, Ali TM, Ashkenani $\mathrm{H}$ (2014) Use of nanoporous $\mathrm{Cu}(\mathrm{II})$ ion imprinted polymer as a new sorbent for preconcentration of $\mathrm{Cu}(\mathrm{II})$ in water, biological and agricultural samples and its determination by electrothermal atomic absorption spectrometry. J AOAC Int 97: 1159-1166.

23. Gilart N, Marce RM, Borrull F, Fontanals N (2012) Determination of pharmaceuticals in wastewaters using solid-phase extraction-liquid chromatography-tandem mass spectrometry. J Sep Sci 35: 875-882.

24. Divya MP, Rajput YS, Sharma R, Singh G (2015) Molecularly imprinted polymer for separation of lactate. J Anal Chem 70: 1213-1217.

25. Chinella I, Guerreiro A, Moczko E, Caygill JS, Piletska EV, et al. (2013) Direct replacement of antibodies with molecularly imprinted polymer nanoparticles in ELISA-Development of a novel assay for vancomycin. Anal Chem 85: 8462-8468.

26. Czulak J, Marcinkowska-Jakubiak A, Trochimczuk A (2013) Polymer catalysts imprinted with ions as biomimics of metalloenzymes. Adv Mater Sci Eng 27: 50-370.

27. Wackerlig J, Lieberzeit PA (2015) Molecularly imprinted polymer nanoparticles in chemical sensing-Synthesis, characterisation and application. Sensors Actuator B: Chemical 207: 144-157.

28. Chen L, Li B (2013) Magnetic molecularly imprinted polymer extraction of chloramphenicol from honey. Food Chem 141: 23-28.

29. Miao SS, Wu MS, Zuo HG, Jiang C, Jin SF, et al. (2015) Core-Shell Magnetic Molecularly Imprinted Polymers as Sorbent for Sulfonylurea Herbicide Residues. J Agr Food Chem 63: 3634-3645.

30. Aggarwal S, Rajput YS, Singh G, Sharma R (2016) Synthesis and characterization of oxytetracycline imprinted polymer for application in food. Appl Nanosci 6: 209-214.

31. Zhang X, Chen L, Xu Y, Wang H, Zeng Q, et al. (2010) Determination of $\beta$-lactam antibiotics in milk based on magnetic molecularly imprinted polymer extraction coupled with liquid chromatography-tandem mass spectrometry. J Chromatogr B 878: 3421-3426.

32. Xie X, Wei F, Chen L, Wang S (2015) Preparation of molecularly imprinted polymers based on magnetic nanoparticles for the selective extraction of protocatechuic acid from plant extracts. J Sep Sci 38: 1046-1052.

33. Zhou Y, Zhou T, Jin H, Jing T, Song B, et al. (2015) Rapid and selective extraction of multiple macrolide antibiotics in food stuff samples based on magnetic molecularly imprinted polymers. Talanta 137: 1-10. 
Citation: Aggarwal S, Rajput YS, Sharma R, Pandey AK (2016) Extraction of Cefquinome from Food by Magnetic Molecularly Imprinted Polymer.

Page 6 of 6

34. Liu M, Li XY, Li JJ, Su XM, Wu ZY, et al. (2015) Synthesis of magnetic molecularly imprinted polymers for the selective separation and determination of metronidazole in cosmetic samples. Anal Bioanal Chem 407: 3875-3880.

35. Xiao D, Wang C, Dai H, Peng J, He J, et al. (2015) Applications of magnetic surface imprinted materials for solid phase extraction of levofloxacin in serum samples. J Mol Recognit 28: 277-284.

36. Lin S, Gan N, Zhang J, Chen X, Cao Y, et al. (2015) A noval reductive graphene oxide-based magnetic molecularly imprinted poly(ethylene-covinyl alcohol) polymers for the enrichment and determination of polychlorinated biphenyls in fish samples. J Mol Recognit 28: 359-368.

37. Ou H, Chen Q, Pan J, Jhang Y, Huang Y, et al. (2015) Selective removal of erythromycin by magnetic imprinted polymers synthesized from chitosan-stabilised Pickering emulsion. J Hazard Mater 289: 28-37.
38. Chen L, Jun L, Quingli Z, Hui LW, Aimin Y, et al. (2009) Preparation of magnetic molecularly imprinted polymer for the separation of tetracycline antibiotics from egg and tissue samples. J Chromatogr A 1216: 3710-3719.

39. Cia W, Gupta RB (2004) Molecularly imprinted polymer selective for tetracycline binding. Sep Purif Technol 35: 215-221.

40. Zhang J, Peppas NA (2000) Synthesis and characterization of $\mathrm{pH}$-and temperature-sensitive poly (methacrylic acid)/poly (Nisopropylacrylamide) interpenetrating polymeric networks. Macromolecules 33: 102-107. 